\title{
UNA PINTURA DE ESCALANTE EN CARDIEL DE LOS MONTES
}

Desde que Lafuente Ferrari prestara atención a Juan Antonio de Frías y Escalante, dedicándole en 1941 un primer artículo, el catálogo de la producción del artista cordobés se ha ido incrementando sustancialmente según se han ido dando a conocer nuevas obras, lo que sin duda ha contribuido a despejar no pocas sombras estilísticas y a conocer algunas particularidades creativas. Sin embargo son escasas las noticias biográficas que se han podido añadir a lo suministrado por Díaz del Valle y Palomino, por lo que se sigue echando en falta el arropamiento documental de muchas de estas creaciones, así como un conocimiento más preciso de diversos aspectos de su vida y de su actividad pictórica.

Frente a algunas atribuciones dudosas ${ }^{1}$ se vienen proponiendo otras más fundamentadas, y ha surgido también algún importante encargo firmado, poco menos que desconocido, como $E l$ tránsito de Santa Clara que preside el altar mayor de la iglesia conventual de las clarisas de Huesca ${ }^{2}$.

A lo recientemente establecido es necesario añadir ahora un Bautismo de Cristo existente en la parroquial de Santiago Apóstol en Cardiel de los Montes (figs. 1 y 2), que se suma a su producción localizada en la provincia de Toledo, con el San Juanito con el cordero ${ }^{3}$ de la parroquia de Santa María en los Yébenes y el San Juan Bautista y la Matanza de los inocentes conservados en la cripta de la Catedral.

Sabido es que la labor de Escalante se desarrolló particularmente en la Corte, donde permaneció activo desde su llegada y entrada al taller de Francisco Rizi, hacia 1650, hasta su muerte, en 1669. A tenor de los datos conocidos y de lo conservado de su obra, sabemos que esencialmente dispuso de una clientela madrileña. A algunos relevantes encargos en la capital, ya tempranos, añade apenas Palomino un par de importantes pinturas fuera de ella, y es posible rastrear la existencia de un elevado número de obras de pequeño formato, aptas para la devoción privada, en inventarios madrileños seiscentistas, aunque en la actualidad son muchas las pinturas dispersas por diferentes localidades españolas y extranjeras, por motivos dispares, y aún se dé a conocer de vez en cuando alguna pintura significativa fuera de la capital, como en el caso que nos ocupa.

Escalante hubo de entrar en contacto con el ámbito toledano a través de su maestro, Francisco Rizi, pintor de la Catedral desde 1653; y el hecho de que aparezca ya en 1655 en calidad de testigo en un documento relacionado con las obras de Rizi en Toledo ${ }^{4}$, y el que éste figure como testamentario a la muerte de su joven discípulo, dan fe de un contacto personal y profesional prolongado y estrecho. Además, según se desprende de Palomino ${ }^{5}$, lo último que hizo

\footnotetext{
${ }^{1}$ Aparte de otras obras ya consideradas, Valverde Madrid («El pintor cordobés Juan Antonio Escalante», Boletín de la Real Academia de Córdoba, de Ciencias, Bellas Letras y Nobles Artes, n. ${ }^{\circ} 125,1993$, p. 63, n. $\left.{ }^{\circ} 17\right)$ le atribuye una Ascensión de la Virgen aparecida en Durán en Abril 1987 n. 213 que además de no semejarse estilística o compositivamente a lo suyo parece obra muy posterior. Tampoco han de ser de su mano el Moisés sacando agua de la roca y La embriaguez de Noé atribuidos en Sothebys, octubre de 1997 n. 109 que aunque representen temas interpretados por el artista en su serie sobre la Eucaristía para la Merced Calzada, no le son propios la factura ni los tipos, y menos el colorido. Aunque muy similar a la Anunciación del Museo Fabregat de Beziers - atribuida al pintor por Lafuente Ferrari-, tampoco ha de ser suya una Anunciación (óleo sobre cobre 22,5 × $29 \mathrm{~cm}$ ) sacada a subasta en Arte Información y Gestión el 20 de noviembre de 2003, que aunque de cierto regusto canesco parece más próxima al ámbito sevillano.

${ }^{2}$ N. Delgado, «Juan Antonio de Frías y Escalante (1663-1669)», Cuadernos de Arte e Iconografía, FUE, tomo X, núm. 20 , p. 284 , cat. 47 , figs. 56 y 57.

${ }^{3}$ Esta pintura que fue dada a conocer por J.M Quesada Valera, «Nueve pinturas madrileñas inéditas del siglo xvII, Goya, núm. 271-272, 1999, pp. 220-222, repite un modelo habitual dentro de la producción del autor dedicada al asunto a la que hay que añadir, ahora, otra de deficiente calidad (65 x 60), aparecida en Alcalá Subastas en febrero de 2003.

${ }^{4}$ AHP: Protocolo 5223, fol 98, recogido por Mercedes Agulló y Cobo en «Antonio y Francisco Rizi», Anales del Instituto de Estudios Madrileños, tomo XXXVI, 1996, p. 86.

${ }^{5}$ A.A Palomino de Castro y Velasco, El Museo Pictórico y Escala Óptica, Madrid, ed. Aguilar, 1947, p. 667.
}

AEA, LXXVII, 2004, 308, pp. 411 a 438 

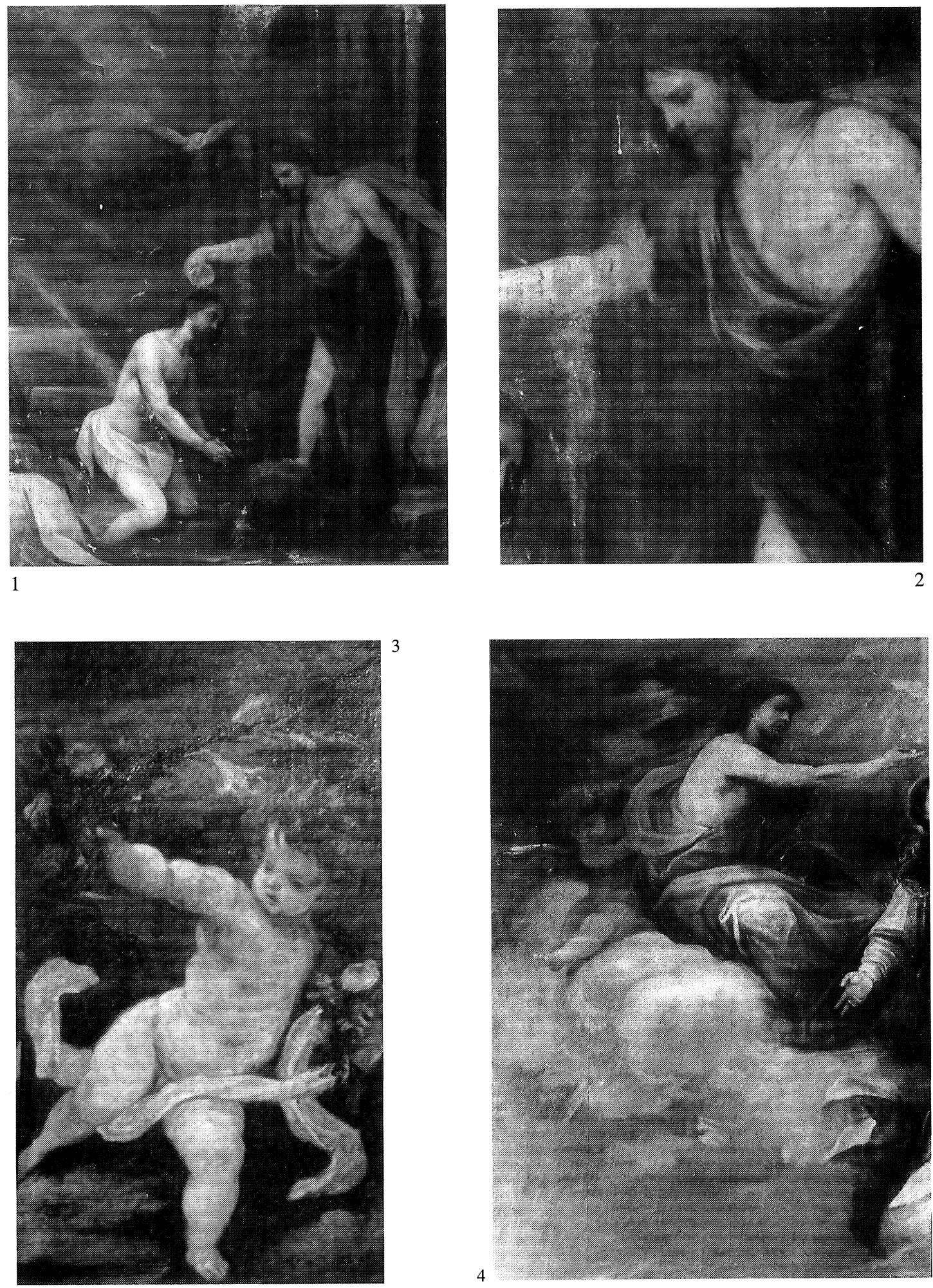

Fig. 1. Bautismo de Cristo.Iglesia parroquial de Cardiel de los Montes.

Fig. 2. Bautismo de Cristo (detalle). Iglesia parroquial de Cardiel de los Montes.

Fig. 3. Retablo de San Francisco de Borja (detalle). Colegiata de San Isidro. Madrid.

Fig. 4. Coronación de la Virgen (detalle). Sacristía de la iglesia del Carmen. Madrid.

AEA, LXXVII, 2004, 308, pp. 411 a 438 
Escalante en lo profesional fue precisamente ayudar a Rizi en la elaboración del Monumento Nuevo para la Catedral Primada, y aunque no hay constancia documental del hecho - las cartas de pago aluden sólo a Rizi y a Carreño, que concertaron la obra-, en la biografía del primero ${ }^{6}$ insiste el tratadista en referir que Escalante y Dionisio Mantuano ayudaron en la elaboración del monumento ${ }^{7}$. Lamentablemente nada subsiste del testimonio pictórico que habría de avalar tal afirmación, pero sí se conservan en la Cripta las dos pinturas realizadas para la Capilla del Sepulcro de la misma catedral, cobradas por Rizi en 1663, en las que se detecta la participación del cordobés ${ }^{8}$.

La relación de Rizi con su discípulo bien pudiera haber proporcionado otras colaboraciones ocasionales. De este modo parece posible que Escalante asistiera a su maestro, en 1658, pintando algunos de los ángeles representados en los cinco compartimentos que conforman el intradós del arco del retablo dedicado a San Francisco de Borja en la Colegiata de San Isidro, antigua Iglesia del Colegio Imperial de los Jesuitas ${ }^{9}$, a juzgar por su tipología y tratamiento pictórico (fig. 3); y en tal sentido cabe mencionar además la existencia de cuatro pinturas alusivas a la vida de la Virgen (Nacimiento, Presentación, Huida a Egipto y Coronación) en la Sacristía de la Iglesia del Carmen de Madrid, en las que se conoce el estilo tanto del discípulo como del maestro. Palomino nos proporciona al respecto una noticia algo equívoca, ya que en la biografía del artista cordobés nos dice que en la sacristía de esta iglesia madrileña había en su tiempo algunas copias de cosa suya ${ }^{10}$. En realidad no sabemos si las cuatro pinturas hoy existentes son aquéllas a las que se refiere el tratadista; pero tres de ellas (Nacimiento, Presentación y Huida a Egipto) parecen más próximas al hacer de Rizi y cercanas en lo figurativo a las del retablo de Fuente del Saz, de 1655, aunque de factura algo desigual, mientras que la cuarta (fig. 4) manifiesta rasgos estilísticos más propios del discípulo, con una figura de Cristo representativa de su admiración por la pintura de Alonso Cano ${ }^{11}$, pudiendo rastrearse tipos muy similares en otras obras propias, incluida la figura del Bautista del lienzo que nos ocupa, y unos ángeles cuyas características formales están en plena consonancia con los referidos del retablo de la Catedral de San Isidro.

Sobre si su estrecha relación con Rizi y su probable presencia en Toledo pudiera haber proporcionado a Escalante algún encargo allí, nada se puede afirmar, pero no parece en todo caso

\footnotetext{
${ }^{6}$ Palomino, op. cit., p. 1017.

${ }^{7}$ Carreño y Rizi llevaban desde 1665 trabajando en la decoración de la capilla de las reliquias y desde 1666 en el camarín de Nuestra Señora del Sagrario, dos obras de ejecución muy lenta y de pagos escalonados hasta 1671 (Zarco del Valle, 1916, pp. 341-343; Pérez Sedano 1914, pp. 104-107).

Según las noticias documentales conservadas Rizi comenzó a pintar el Monumento nuevo en junio de 1668, aunque la escritura no se hizo hasta enero de 1669 , que es el momento en que empieza a pintar Carreño. Escalante fallece seis meses después, y las obras no se terminan hasta 1672. Si es cierta la aseveración de Palomino, que hay que advertir, atrasa el fallecimiento del pintor un año, Escalante debió de participar en la elaboración de alguno de los dieciocho lienzos que se le pagaron a Rizi en mayo de 1670 , que son los primeros que el maestro cobra por el encargo. Todo lo referido al encargo y sus pagos está recogido por Pérez Sedano en op. cit., 1914, pp. 104-107.

${ }^{8}$ Ya D. Diego Angulo Iñiguez apuntó las anałogías entre el San Juan Bautista y el estilo de Escalante en «Francisco Rizi. Su vida. Cuadros religiosos fechados anteriores a 1970», Archivo Español de Arte, XXXI, (1958), p. 113.

${ }^{9}$ A Rizi se le encargaron dos retablos colaterales del crucero, uno dedicado a San Luis Gonzaga, íntegramente destruido durante la guerra civil y el otro éste de San Francisco de Borja, salvado en parte del que se conserva el lienzo titular, preservado en la sacristía, las figuras de San Pedro y San Pablo en el grueso del muro y los cinco ángeles en el intradós.

${ }^{10}$ Palomino, op. cit., p. 967. Respecto a esta noticia de Palomino nada nos dice Ceán Bermúdez y llama la atención al respecto el silencio de Antonio Ponz y de D. Elías Tormo.

${ }^{11}$ Esta figura y algún otro detalle compositivo como el modo en que se recoge la escena situando un ángel junto a ésta y otro al contrario, asomándose tras la figura de Dios Padre, son detalles que pudieran suponer una directa inspiración de Escalante en una composición de Cano que conocemos a través de un dibujo conservado en los Uffizi que representa a la Virgen arrodillada ante la Trinidad y que Sánchez Cantón, Dibujos españoles. IV Alonso Cano, Ministerio de Instrucción Pública y Bellas Artes, 1930, lám. CCCXI, interpretó acertadamente como boceto para el ático del desaparecido retablo de la Inmaculada Concepción del Colegio Imperial que el granadino ejecutó durante sus primeros años en Madrid y que Escalante tuvo que conocer forzosamente.
}

$A E A$, LXXVII, 2004, 308, pp. 411 a 438 
que el lienzo de Cardiel de los Montes fuera encargo para tan modestísima iglesia parroquial - por entonces sólo ermita ${ }^{12}$ — ni que éste, por tanto, fuera su emplazamiento original. En los libros parroquiales de fábrica no consta pago alguno en concepto de pintura en los años en que pudo haber sido efectuado el encargo, pero tampoco nada que haga referencia a una donación posterior, por lo que desconocemos en qué momento y circunstancias llegó a su actual paradero.

A pesar de su mal estado de conservación, es obra que no plantea problemas o dudas de autoría. De dimensiones importantes $(1,60 \times 1,90 \mathrm{~m}$.), es pintura de no modestas pretensiones y cuyo conocimiento viene a enriquecer, sin duda, el catálogo de su producción.

Comparecen en ella los ingredientes estilísticos fundamentales de su arte, los mismos que, en origen, sirvieron a los principales artistas de su generación asentados en la Corte. No hace falta insistir en la evidente influencia que ejerció en gran parte de ellos tanto la pintura flamenca del s. XVII como la veneciana del siglo precedente. Escalante no fue ajeno así al influjo de Rubens o de Van Dyck, y ya Palomino ${ }^{13}$ destacó la afición que tuvo su paisano a Tintoretto y Veronés, señalando también a Tiziano al hablar en particular del magnífico Cristo muerto que antaño estuviera en la Iglesia del Espíritu Santo de Madrid. También su formación con Francisco Rizi se hace evidente, pero, aunque en sus obras refleja siempre de algún modo la impronta del maestro, en general subyace una particular inclinación hacia los modelos de Alonso Cano que parece trascender lo estrictamente formal.

Todas estas sugestiones, hábilmente adaptadas a su propia concepción y estilo, así como un modo muy singular de utilizar el color, lo convierten en un pintor original y de sensibilidad más reposada y clásica dentro del panorama artístico madrileño del momento. Es por ello que no resulta difícil establecer una serie de valoraciones y semejanzas formales con el resto de su producción que suplan la ausencia de firma en la obra.

Como creador de unos tipos muy personales y reconocibles en lo fisiognómico y en lo postural, tanto la figura del Bautista como la de Cristo son modelos ya plasmados en otras composiciones. Así, se constata la utilización para Cristo del modelo figurativo del San José de la Colección Stromfelt que dio a conocer Méndez Casal ${ }^{14}$, en facciones y expresión, y la concepción de la figura del Bautista, derivación de sus tipos de inspiración canesca, guarda una evidente relación con el San José que fue de la colección Adanero y hoy del Museo de Bellas Artes de Oviedo ${ }^{15}$ - la inspiración arranca sin duda de la pintura del granadino en el retablo de Nuestra Señora de la Paz de la Magdalena de Getafe-, si bien no hay que ocultar que en la composición de Cardiel de los Montes se observa una ligera torpeza a la hora de desarrollar la pierna derecha del santo, lo que no deja de sorprender, dado que su escorzo evoca modelos de otras obras salidas de su mano y ya desde fechas tempranas mostró soltura en la ejecución anatómica de sus tipos. No descuida sin embargo los pormenores, y como en el temprano Cristo camino del Calvario de la Academia de San Fernando se muestra muy hábil en el tratamiento de los detalles naturalistas, como las pequeñas flores ubicadas en el margen inferior. Particularmente característica es la figura de Dios Padre, rastreable en otras pinturas propias, y no menos representativas son las tímidas cabezas de querubines que emergen de las nubes.

Mostrando siempre gran habilidad para lo colorístico y una particular elegancia en las gradaciones tonales, Escalante hace uso aquí de una gama cálida de ocres, sepias y anaranjados, sin descuidar los azules verdosos del celaje, resuelto en consonancia con su característico modo de hacer a base de pinceladas ligeras y transparentes que dejan ver diferentes tonalidades y matices. Probablemente una restauración nos descubra una pintura más luminosa, pues, eviden-

\footnotetext{
${ }^{12}$ Así consta en algunos de los libros, luego parroquiales.

${ }^{13}$ Palomino, op. cit., p. 967.

${ }^{14}$ Méndez Casal, «La pintura antigua española en Escandinavia», Revista Española de Arte, 1936, p. 6, lám. XIX.

15 Transitoriamente en la galería Caylus de Madrid, en 1995.
} 
temente, tanto la suciedad acumulada como la humedad que ha provocado el destensamiento del lienzo y, por consiguiente, el craquelado de la superficie pictórica, lo desvirtúan.

En lo cronológico sólo cabe apuntar que hemos de estar ante una pintura ejecutada por la primera mitad de la década de los sesenta, antes de la realización de su encargo para la Merced Calzada de Madrid (1667-1668), ya que existen ciertas similitudes estilísticas con pinturas inmediatamente anteriores a éstas, como el citado San José con el Niño, San Juanito y dos ángeles o el San Juan Bautista subastado en la sala La Habana en abril del año 2000.

Natalia Delgado Martínez

\section{EL MARTIRIO DE SAN PELAYO: UNA OBRA DESCONOCIDA DEL PINTOR MARTÍN AMIGO EN BELENDIZ (BIZKAIA).}

Dentro del cada vez más difundido y revalorizado panorama de la pintura barroca desarrollada en el País Vasco ${ }^{1}$ nos reencontramos aquí con una de sus figuras señeras durante el siglo XVII. Concretamente hablamos de Martín Amigo, pintor de origen alavés y vecino de Bilbao durante gran parte de su vida, a cuya personalidad y obra artística nos acercó en su momento el profesor Barrio Loza ${ }^{2}$. Volvemos a él con ocasión de presentar ahora un cuadro inédito conservado en la ermita de San Pelayo de Belendiz en la localidad vizcaína de Arratzu a cuya parroquia de Santo Tomás Apóstol sirve aquélla como aneja. Se trata de un óleo sobre lienzo que reproduce el martirio del santo titular, de aproximadamente $1,50 \times 2,20$ metros y regular estado de conservación, y que está firmado («Amigo ft.») y fechado (1680) en su ángulo inferior derecho. Además de acercarnos al cuadro desde diferentes ángulos, su análisis nos servirá también para intentar redondear el perfil artístico y biográfico de un artista perteneciente al pleno barroco, que da el salto del oficio de pintor-dorador desarrollado por su familia a la gran pintura, la de caballete, en la que se nos muestra dotado de una gran cultura visual al componer «historias» mezclando diferentes fuentes gráficas.

Desconocemos cómo pudo llegar a este pequeño templo una obra del interés que atesora la que comentamos ya que no tenemos constancia documental del nombre del comitente o los avatares históricos que la condujeron a su actual ubicación pero es posible que fuese el señor de la Torre de Belendiz, históricamente relacionada con la ermita y de la que está separada por escasos metros, quien se encargase de dotar al templo de la imagen del patrón que, por otra parte, aparece estrechamente relacionado con el Camino de Santiago y la cristianización del norte peninsular ${ }^{3}$.

\footnotetext{
${ }^{1}$ Tabar Anitua, F.: «La pintura del Barroco en Euskal Herria. Arte local e importado», Ondare, Donostia-San Sebastián, $\mathrm{n}^{\mathrm{o}}$ 19, 2000, pp. 117-149. Nos ofrece una síntesis de la pintura barroca del País Vasco y Navarra. Un posterior acercamiento lo tenemos en Vélez Chaurri, J.J. y Echeverría Goñi, P.L.: «Pintura barroca con vinculación histórica al País Vasco» en Oropesa, M. (Comisaria): Luces del Barroco. Pintura y escultura del siglo xVII en España (Catálogo de la exposición), Vitoria-Gasteiz, Fundación Caja Vital Kutxa y Departamento de Cultura de la Diputación Foral de Álava, 2002, pp. 21-31.

${ }^{2}$ Barrio Loza, J.A.: «Nota sobre un pintor barroco vasco mal conocido: Martín Amigo», Urtekaria/Anuario (Museo de Bellas Artes de Bilbao/Bilboko Arte Ederretako Museoa), Bilbao, 1989, pp. 35-40. Al reconocimiento de su importancia en la pintura barroca vasca han contribuido después tanto Pérez Sánchez, A.E.: Pintura barroca en España, 1600-1750, Madrid, Cátedra, 1992, p. 347 como Tabar Anitua, F.: Op. Cit., p. 126 y Vélez Chaurri, J.J. y Echeverría Goñi, P.L.: $O p$. Cit., pp. 30-31.

${ }^{3}$ Arregi, G.: Ermitas de Bizkaia, tomo I, Diputación Foral de Bizkaia, Bilbao, 1987, p. 43. Refiere que según Iturriza, historiador vizcaíno del siglo xvIII, fue fundado por la Casa solar de Belendiz en la centuria anterior. Realmente lo que obedece a ésta es la reforma del edificio pues ciertos elementos, como el arco de ingreso, nos hablan de su construcción durante el Gótico, época a la que también corresponde la mencionada Torre. A la relación de Pelayo con la ruta jacobea, nos acerca por ejemplo, Portilla, M.J.: Una ruta europea. Por Álava, a Compostela. Del Paso de San Adrián, al Ebro,
}

$A E A$, LXXVII, 2004, 308, pp. 411 a 438 